\title{
State-of-Art of Transonic Axial Compressors
}

\author{
Roberto Biollo and Ernesto Benini \\ University of Padova \\ Italy
}

\section{Introduction}

Transonic axial flow compressors are today widely used in aircraft engines to obtain maximum pressure ratios per single-stage. High stage pressure ratios are important because they make it possible to reduce the engine weight and size and, therefore, investment and operational costs. Performance of transonic compressors has today reached a high level but engine manufacturers are oriented towards increasing it further. A small increment in efficiency, for instance, can result in huge savings in fuel costs and determine a key factor for product success. Another important target is the improvement of rotor stability towards near stall conditions, resulting in a wider working range.

Important analytical and experimental researches in the field of transonic compressors were carried out since 1960's (e.g. Chen et al., 1991; Epstein, 1977; Freeman \& Cumpsty, 1992; König et al., 1996; Miller et al., 1961; Wennerstrom \& Puterbaugh, 1984). A considerable contribution for the new developments and designs was the progress made in optical measurement techniques and computational methods, leading to a deeper understanding of the loss mechanisms of supersonic relative flow in compressors (e.g. Calvert \& Stapleton, 1994; Hah \& Reid, 1992; Ning \& Xu, 2001; Puterbaugh et al., 1997; Strazisar, 1985; Weyer \& Dunker, 1978). Fig. 1 shows the low pressure and high pressure compressors of the EJ200 engine as examples for highly loaded, high performance transonic rotors of an aero engine. A closer look at the current trend in design parameters for axial flow transonic compressors shows that, especially in civil aircraft engines, the relative flow tip Mach number of the rotor is limited to maintain high efficiencies. A typical value for the rotor inlet relative flow at the tip is Mach $\approx 1.3$. The continuous progress of aerodynamics has been focused to the increase in efficiency and pressure ratio and to the improvement in off-design behaviour at roughly the same level of the inlet relative Mach number. Today's high efficiency transonic axial flow compressors give a total pressure ratio in the order of 1.7-1.8, realized by combining high rotor speeds (tip speed in the order of $500 \mathrm{~m} / \mathrm{s})$ and high stage loadings $\left(2 \Delta \mathrm{h} / \mathrm{u}^{2}\right.$ in the order of 1.0). The rotor blade aspect ratio parameter showed a general trend towards lower values during past decades, with a current asymptotic value of 1.2 (Broichhausen \& Ziegler, 2005).

The flow field that develops inside a transonic compressor rotor is extremely complex and presents many challenges to compressor designers, who have to deal with several and concurring flow features such as shock waves, intense secondary flows, shock/boundary layer interaction, etc., inducing energy losses and efficiency reduction (Calvert et al., 2003; Cumpsty, 1989; Denton \& Xu, 1999; Law \& Wadia, 1993; Sun et al., 2007). Interacting with secondary flows, shock waves concur in development of blockage (Suder, 1998), in corner 
stall separation (Hah \& Loellbach, 1999; Weber et al., 2002), in upstream wakes destabilization (Estevadeordal et al., 2007; Prasad, 2003), and in many other negative flow phenomena. Particularly detrimental is the interaction with the tip clearance flow at the outer span of the rotor, where the compressor generally shows the higher entropy production (Bergner et al., 2005a; Chima, 1998; Copenhaver et al., 1996; Gerolymos \& Vallet, 1999; Hofmann \& Ballmann, 2002; Puterbaugh \& Brendel, 1997; Suder \& Celestina, 1996).
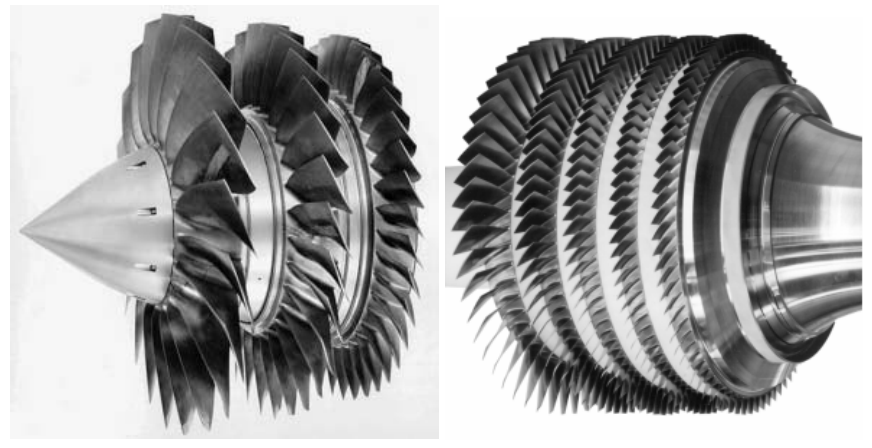

Fig. 1. Transonic LPC (left) and HPC (right) of the Eurofighter Typhoon engine EJ200 (Broichhausen \& Ziegler, 2005)

As the compressor moves from peak to near-stall operating point, the blade loading increases and flow structures become stronger and unsteady. The tip leakage vortex can breakdown interacting with the passage shock wave, leading to not only a large blockage effect near the tip but also a self-sustained flow oscillation in the rotor passage. As a result, the blade torque, the low energy fluid flow due to the shock/tip leakage vortex interaction and the shock-induced flow separation on the blade suction surface fluctuate with time (Yamada et al., 2004).

Despite the presence of such flow unsteadiness, the compressor can still operate in a stable mode. Rotating stall arises when the loading is further increased, i.e. at a condition of lower mass flow rate. Two routes to rotating stall have been identified: long length-scale (modal) and short length-scale (spike) stall inception in axial compressors (Day, 1993). Modal stall inception is characterized by the relatively slow growth (over 10-40 rotor revolutions) of a small disturbance of long circumferential wavelength into a fully developed stall cell. Spike stall inception starts with the appearance of a large amplitude short length-scale (two to three rotor blade passages) disturbance at the rotor tip, the so-called spike, which grows into a fully developed rotating stall cell within few rotor revolutions.

The following paragraphs give a summary of the possible techniques for limiting the negative impacts of the above reported compressor flow features in aircraft gas turbine engines.

\section{Blade profiles studies}

For relative inlet Mach numbers in the order of 1.3 and higher the most important design intent is to reduce the Mach number in front of the passage shock. This is of primary importance due to the strongly rising pressure losses with increasing pre-shock Mach number, and because of the increasing pressure losses due to the shock/boundary layer 
interaction or shock-induced separation. The reduction of the pre-shock Mach number can be achieved by zero or even negative curvature in the front part of the blade suction side and by a resulting pre-compression shock system reducing the Mach number upstream of the final strong passage shock.

Besides inducing energy losses, the presence of shock waves makes transonic compressors particularly sensitive to variations in blade section design. An investigation of cascade throat area, internal contraction, and trailing edge effective camber on compressor performance showed that small changes in meanline angles, and consequently in the airfoil shape and passage area ratios, significantly affect the performance of transonic blade rows (Wadia \& Copenhaver, 1996).

One of the most important airfoil design parameter affecting the aerodynamics of transonic bladings is the chordwise location of maximum thickness. An experimental and numerical evaluation of two versions of a low aspect ratio transonic rotor having the location of the tip blade section maximum thickness at $55 \%$ and $40 \%$ chord length respectively, showed that the more aft position of maximum thickness is preferred for the best high speed performance, keeping the edge and maximum thickness values the same (Wadia \& Law, 1993). The better performance was associated with the lower shock front losses with the finer section that results when the location of the maximum thickness is moved aft. The existence of an optimum maximum thickness location at $55 \%$ to $60 \%$ chord length for such rotor was hypothesized. Similar results can be found in a recent work (Chen et al., 2007) describing an optimization methodology for the aerodynamic design of turbomachinery applied to a transonic compressor bladings and showing how the thermal loss coefficient decreases with increasing the maximum thickness location for all the sections from hub to tip.

Not only the position of maximum thickness but also the airfoil thickness has been showed to have a significant impact on the aerodynamic behaviour of transonic compressor rotors, as observed in an investigation on surface roughness and airfoil thickness effects (Suder et al., 1995). In this work, a $0.025 \mathrm{~mm}$ thick smooth coating was applied to the pressure and suction surface of the rotor blades, increasing the leading edge thickness by $10 \%$ at the hub and $20 \%$ at the tip. The smooth coating surface finish was comparable to the bare metal blade surface finish; therefore the coating did not increase roughness over the blade, except at the leading edge where roughness increased due to particle impact damage. It resulted in a $4 \%$ loss in pressure ratio across the rotor at an operating point near design mass flow, with the largest degradation in pressure rise over the outer half of the blade span. When assessed at a constant pressure ratio, the adiabatic efficiency degradation at design speed was in the order of 3-6 points.

The recent development of optimization tools coupled with accurate CFD codes has improved the turbomachinery design process significantly, making it faster and more efficient. The application to the blade section design, with a quasi three-dimensional and more recently with a fully three-dimensional approach, can lead to optimal blade geometries in terms of aerodynamic performance at both design and off-design operating conditions. Such a design process is particularly successful in the field of transonic compressors, where performance is highly sensitive to little changes in airfoil design.

Fig. 2 shows the blade deformation obtained in a quasi 3-D numerical optimization process of a transonic compressor blade section along with the relative Mach number contours before and after the optimization (Burguburu et al., 2004). As shown, no modifications of the 
inlet flow field occurred after optimization but the flow field structure in the duct is clearly different. The negative curvature of the blade upstream of the shock led to the reduction of the upstream relative Mach number from 1.4 to 1.2. With this curvature change, the velocity slowdown is better driven. Instead of creating a normal shock, the new shape created two low intensity shocks. The new blade gave an efficiency increment of 1.75 points at design condition, without changing the choking mass flow. A large part of the efficiency improvement at the design condition remained at off-design conditions.
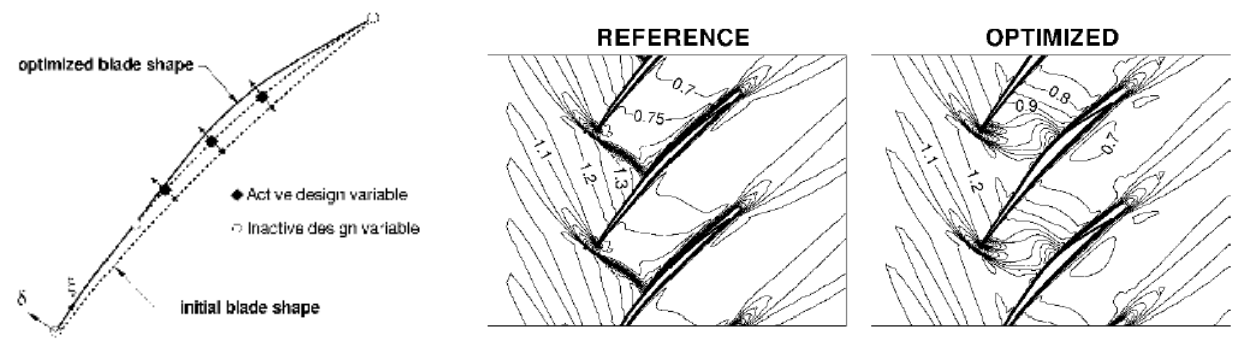

Fig. 2. Blade deformation (left) and relative Mach number contours (right) before and after optimization (Burguburu et al., 2004)

Fig. 3 is related to a both aerodynamic and structural optimization of the well-known transonic compressor rotor 67 (Strazisar et al., 1989), where the aerodynamic objective aimed at maximizing the total pressure ratio whereas the structural objective was to minimize the blade weight, with the constraint that the new design had comparable mass flow rate as the baseline design (Lian \& Liou, 2005). The optimization was carried out at the design operating point. Geometric modifications regarded the mean camber line (with the leading and trailing edge points fixed) and thickness distribution of four airfoil profiles (hub, 31\% span, $62 \%$ span, and tip), linearly interpolated to obtained the new 3-D blade. The chord distribution along the span and the meridional contours of hub, casing, sweep, and lean were maintained.
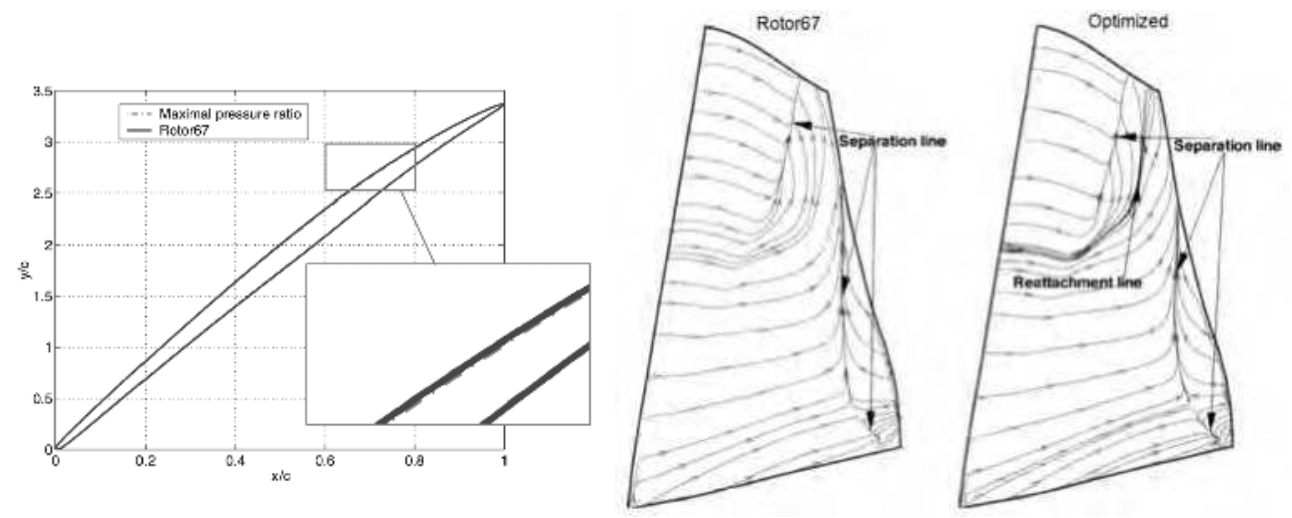

Fig. 3. Blade section at $90 \%$ span (left) and streamlines close to the blade suction side (right) before and after the optimization (modified from Lian \& Liou, 2005) 
At $10 \%$ and $50 \%$ span (not shown here), the optimization gave a larger camber but lower thickness than the baseline design. The thinner airfoils contributed to reduce the weight of the new design. The calculated difference in the pressure distribution was rather small. At $90 \%$ span (see Fig. 3), the new design had a slightly smaller camber and thinner airfoil than the baseline. Nevertheless, the calculated pressure difference was rather large, indicating again that transonic flow is highly sensitive to the profile shape change. One noticeable impact was also in the shock position. The new design showed a more forward passage shock than the baseline.

Such optimized blade gave a decrease of $5.4 \%$ in weight and an improvement of $1.8 \%$ in the total pressure ratio. The lighter weight came from the thinner blade shape. The higher total pressure ratio was mainly attributed to a reduced separation zone after the shock at the outer span. In Fig. 3, the separation zones are characterized by streamlines going towards the separation lines, whereas reattachment lines look like flow is going away from the separation lines. Compared with the baseline design, downstream of the shock the new design gave a smaller separation zone, which was partially responsible for its higher total pressure ratio.

Fig. 4 is again related to the redesign of rotor 67 using an optimization tool based on evolutionary algorithms (Oyama et al., 2004). Note the particular new design, an improbable design using manual techniques. The optimization gave rise to a double-hump blade shape, especially obvious on the pressure side.

In such new design, the flow acceleration near the leading edge at $33 \%$ span diminished because of the decrease of the incidence angle. In addition, at the $90 \%$ span, the shock on the suction side moved aft and was weakened considerably because of the aft movement of the maximum camber position. This new blade showed an overall adiabatic efficiency of $2 \%$ higher than the baseline blade over the entire operating range for the design speed.
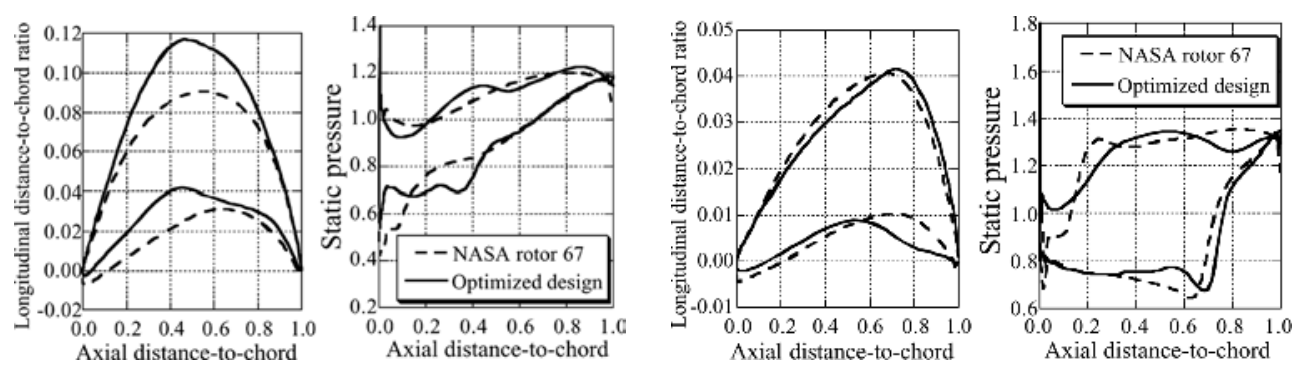

Fig. 4. Comparison between the optimized and baseline design at 33\% and $90 \%$ span

(Oyama et al., 2004)

\section{Three-dimensional shaped bladings}

The preceding paragraph has shown that a certain maturity in transonic compressors has been reached regarding the general airfoil aerodesign. But the flow field in a compressor is not only influenced by the two-dimensional airfoil geometry. The three-dimensional shape of the blade is also of great importance, especially in transonic compressor rotors where an optimization of shock structure and its interference with secondary flows is required. Many experimental and numerical works can be found in the literature on the design and analysis of three-dimensional shaped transonic bladings (e.g. Copenhaver et al., 1996; Hah et al., 
2004; Puterbaugh et al., 1997). Fig. 5 shows two examples of non-conventional rotors (Rotor2 and Rotor3) derived from the baseline Rotor1 which is conventionally radially-stacked, all developed by TU Darmstadt and MTU Aero Engines. As far as their performance is concerned, Rotor2 gave no real improvement in efficiency and total pressure ratio with respect to the baseline configuration (Blaha et al., 2000; Kablitz et al., 2003a). Rotor3, instead, gave higher performance at design speed (1.5\% peak efficiency increment) along with a significantly wider operating range (Passrucker et al., 2003). Information on the favourable impact of Rotor3 blade design on internal transonic flow field is available in the open literature (Bergner et al., 2005b; Kablitz et al., 2003b).
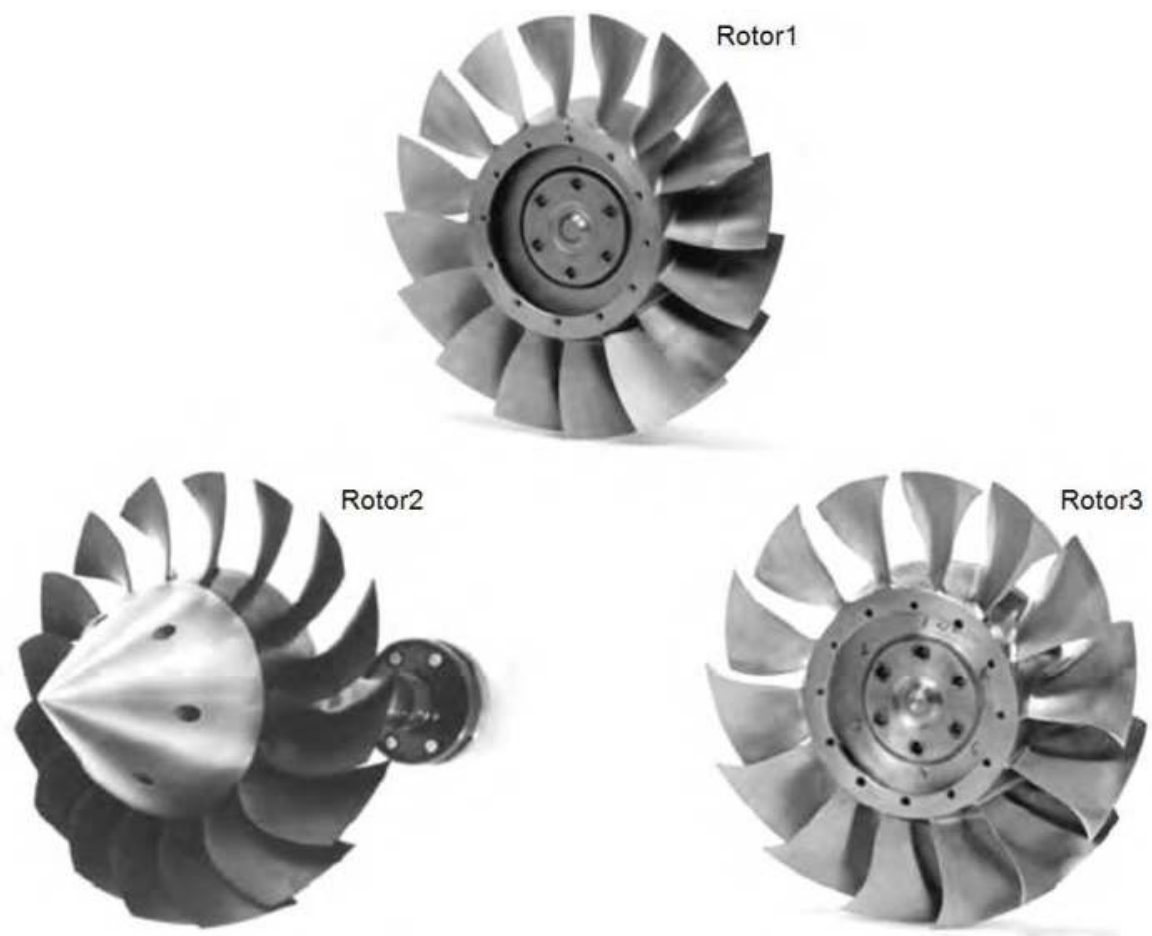

Fig. 5. Transonic compressor test rotors - TU Darmstadt and MTU Aero Engines (Broichhausen \& Ziegler, 2005; Passrucker et al., 2003)

A numerical investigation on the aerodynamics of 3-D shaped blades in transonic compressor rotors showed the possibility to have better stall margin with forward sweep (upstream movement of blade sections along the local chord direction, especially at outer span region), maintaining a high efficiency over a wider range (Denton, 2002; Denton \& Xu, 2002). This seems to be a general point of view, as confirmed by the following researches.

Numerical and experimental analyses carried out to evaluate the performance of a conventional unswept rotor, a forward swept rotor and an aft swept rotor showed that the forward swept rotor had a higher peak efficiency and a substantially larger stall margin than the baseline unswept rotor, and that the aft swept rotor had a similar peak efficiency with a significantly smaller stall margin (Hah et al., 1998). Detailed analyses of the measured and 
calculated flow fields indicated that two mechanisms were primarily responsible for the differences in aerodynamic performance among these rotors. The first mechanism was a change in the radial shape of the passage shock near the casing by the endwall effect, and the second was the radial migration of low momentum fluid to the blade tip region. Similar results were obtained in a parallel investigation which identified the reduced shock/boundary layer interaction, resulting from reduced axial flow diffusion and less accumulation of centrifuged blade surface boundary layer at the tip, as the prime contributor to the enhanced performance with forward sweep (Wadia et al., 1998).
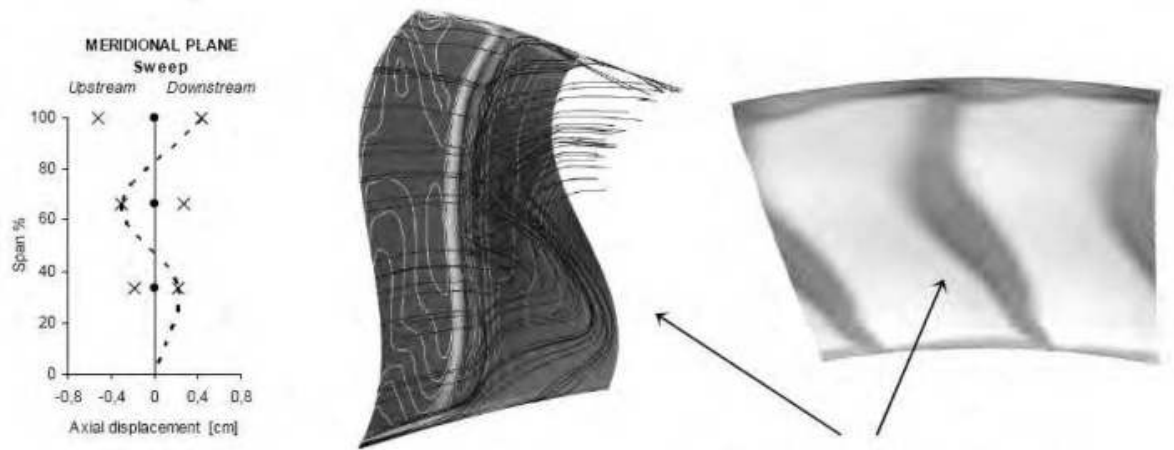

A strong radial outward fluid migration inside the boundary layer has a negative impact on the local blade wake development
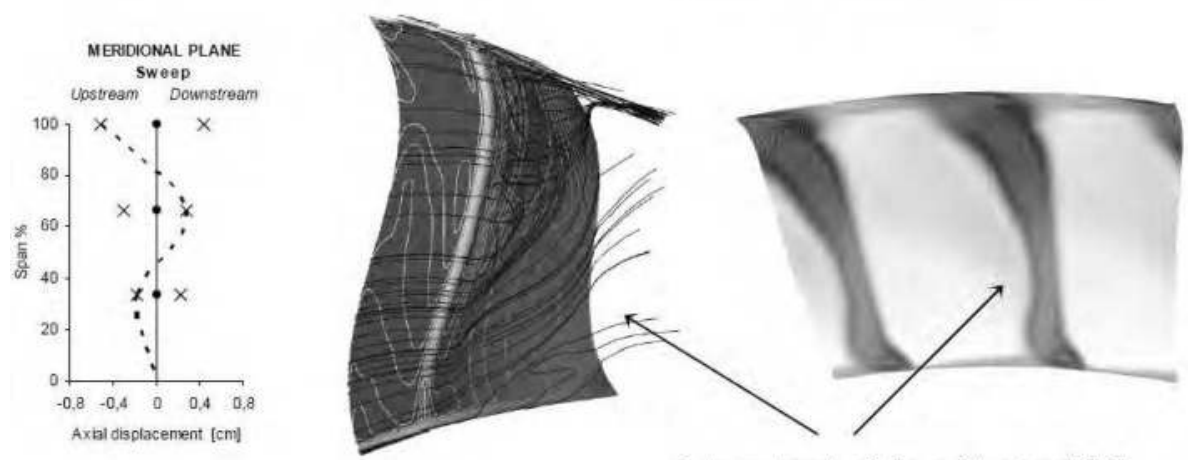
A lower strength of the radial outward fluid
migration inside the boundary layer helps to
reduce the local circumferential blade wake
thickness

Fig. 6. Blade axial curvature impact on shock, suction side boundary layer and blade wake development (Biollo \& Benini, 2008a)

A recent numerical work gave another point of view on the impact of blade curvature in transonic compressor rotors, showing how the movement of blade sections in the axial direction can influence the internal flow field (Benini \& Biollo, 2007; Biollo \& Benini, 2008a). Such work showed that the axial blade curvature can help to influence the shock shape in the meridional plane, inducing the shock to assume the meridional curvature of the blade leading edge (Fig. 6). In addition, a considerable impact on the radial outward migration of 
fluid particles which takes place inside the blade suction side boundary layer after the interaction with the shock has been confirmed. The code predicted a reduction of the strength of such flow feature when the blade is curved downstream and an increment when the blade is curved upstream. Such flow phenomenon is harmful because obstructs the boundary layer development in the streamwise direction, leading to a thickening of blade wakes. A reduction of its strength helped to reduce the entropy generation and the aerodynamic losses associated with the blade wake development. The possibility to increase the peak efficiency of $0.8 \%$ at design speed using a proper downstream blade curvature has been showed for the high loaded transonic compressor rotor 37. Details on rotor 37 can be found in the open literature (Reid \& Moore, 1978).

The same research group investigated the aerodynamic effects induced by several tangential blade curvatures on the same rotor. It was observed that, when the curvature is applied towards the direction of rotor rotation, the blade-to-blade shock tends to move more downstream, becoming more oblique to the incoming flow. This reduced the aerodynamic shock losses and entropy generation, showing in some cases a peak efficiency increment of over $1 \%$ at design speed (Benini \& Biollo, 2008). Similar results were previously obtained using a numerical optimization algorithm (Ahn \& Kim, 2002). Fig. 7 shows the predicted impact of the optimized design of rotor 37 on the blade-to-blade Mach number.
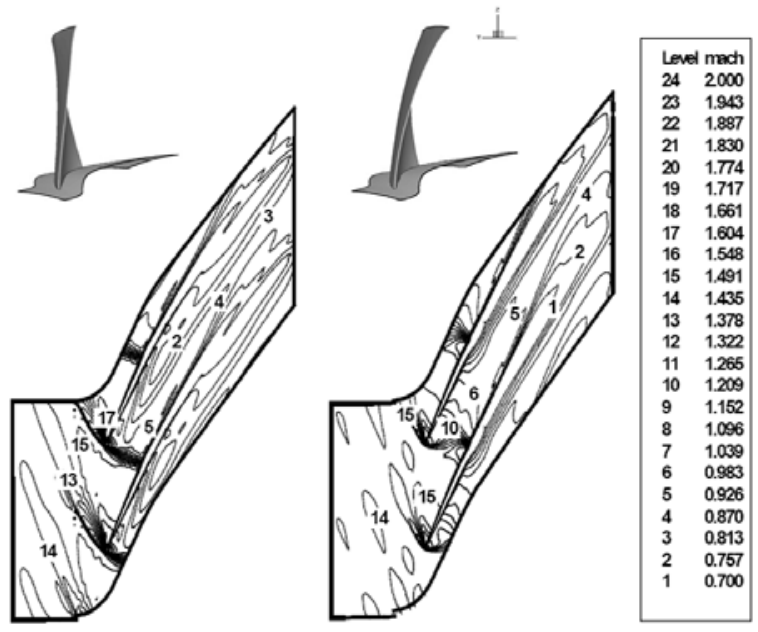

Fig. 7. Baseline (left) and optimized (right) Mach number distributions at $90 \%$ span (modified from Ahn \& Kim, 2002)

Higher performance can be achieved using a proper combination of two orthogonal blade curvatures, i.e. the use of a blade curved both axially and tangentially, as well as swept and leaned at the same time. Peak efficiency increments from $1 \%$ to $1.5 \%$ were numerically observed using a blade prevalently curved towards the direction of rotor rotation and slightly backward inclined (Biollo \& Benini, 2008b; Jang et al., 2006; Yi et al., 2006).

\section{Casing treatments}

Hollow structures in the casing to improve the tip endwall flow field of axial flow compressors are commonly referred to as casing treatments. Fig. 8 shows some examples of 
casing treatments investigated in the 1970's. The interaction of the main flow with the flow circulating in these cavities seems to have a positive impact on rotor stability. However, early studies did not reach a detailed understanding of the phenomenon, since experimental investigations were too expensive and only few configurations could be tested. Only in the past fifteen years numerical simulations made it possible to investigate a larger number of casing treatment solutions and their effects on different compressors. Many researches were carried out on transonic compressor rotors and the potential of this kind of passive devices was revealed: a proper treatment can not only widen the stable working range of a transonic compressor rotor, but also improve its efficiency.

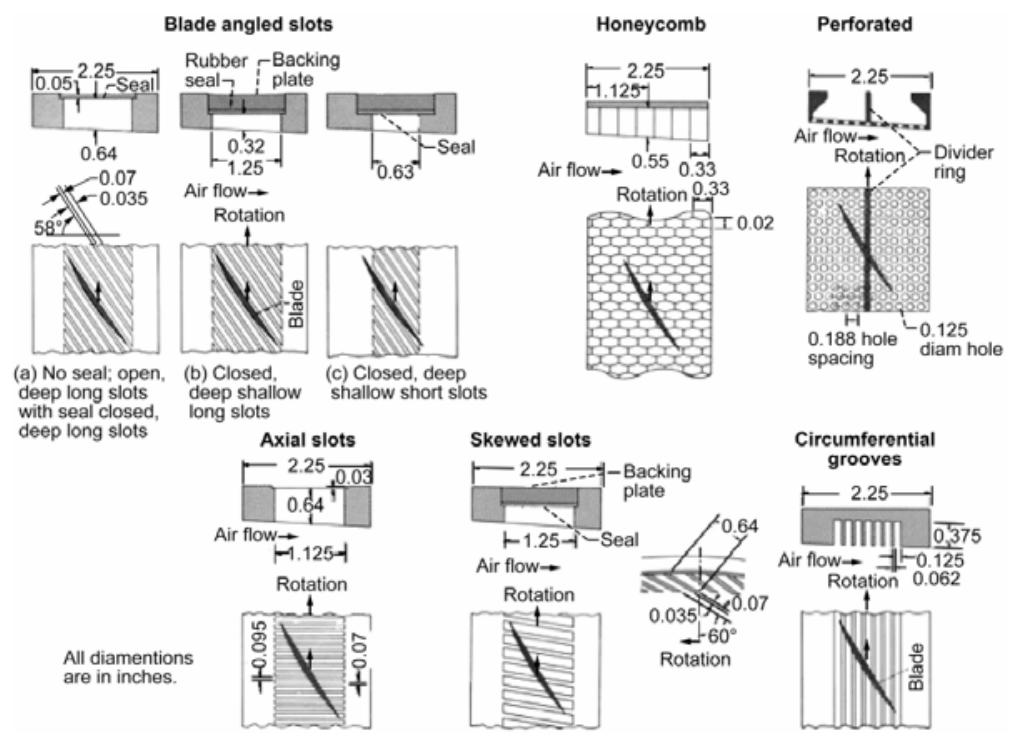

Fig. 8. Various casing treatments investigated in the 1970's (Hathaway, 2007)

\subsection{Circumferential groove-type treatments}

Recently, the influence of circumferential grooves on the tip flow field of an axial singlestage transonic compressor has been examined both experimentally and numerically (Fig. 9). The compressor stage provided a strongly increased stall margin (56.1\%), with only small penalties in efficiency when the casing treatment was applied. Flow analyses showed that at near stall conditions with the smooth casing, the induced vortex originating from the tip clearance flow crossing the tip gap along $20-50 \%$ chord length, hits the front part of the adjacent blade, indicating the possibility of a spill forward of low momentum fluid into the next passage, a flow feature considered a trigger for the onset of rotating stall. With the casing treatment applied, the vortex trajectory remained instead aligned to the blade's suction side.

Disadvantages of casing treatments like these are the space they need and the weight increase of the compressor casing. So it is a goal to maintain the positive effects (increased surge pressure ratio in combination with high efficiency) while at the same time reducing the geometric volume of the device. On this regard, an experimental and numerical investigation on the first rotor of a two-stage compressor showed that grooves with a much 
smaller depth than conventional designs are similarly effective in increasing the stall margin (Rabe \& Hah, 2002). The same work also showed that two shallow grooves placed near the leading edge are better than five deep or shallow grooves all over the blade tip. Fewer shallower grooves clearly help to reduce the weight, fabrication costs, and loss generation associated with such a casing treatment.
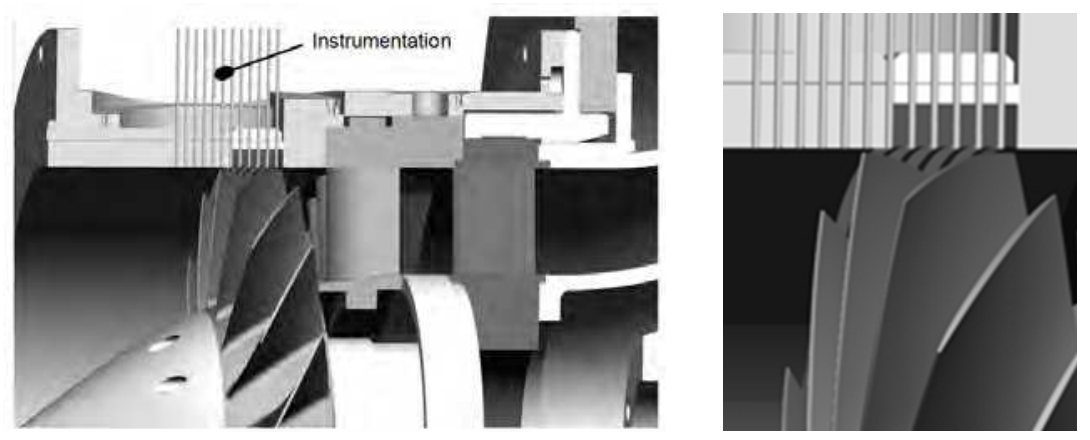

Fig. 9. Cross section of a transonic compressor stage with circumferential grooves (modified from Müller et al., 2008)

Other possible groove-type casing treatment solutions are presented in Figs. 10 and 11. Fig. 10 shows a single extended casing circumferential groove all over the blade tip section. It has been numerically shown that such a casing treatment provides a means for fluid to exit the flow path where the blade loading is severe, migrate circumferentially, and re-enter the flow path at a location where the pressure is more moderate. This can lead to stability improvement since the flow relocation helps to relieve the locally severe blade loading. Using this device, the authors showed the possibility to improve both the efficiency and the stall margin.

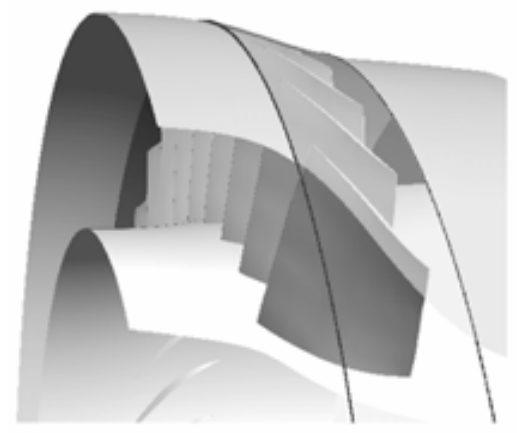

Fig. 10. Single extended casing circumferential groove (Beheshti et al., 2004)

Fig. 11 is related to a numerical investigation of casing contouring effects on flow instability. While the "Type B1" solution gave no improvements in stall margin, the "Type C2" solution extended the calculated stable operating range from $94 \%$ to about $92.5 \%$ normalized mass flow. With respect to the baseline smooth casing configuration, the successful contouring 
induced a smaller inflow angle near the leading edge, i.e. a lower incidence, delaying rotating stall inception.

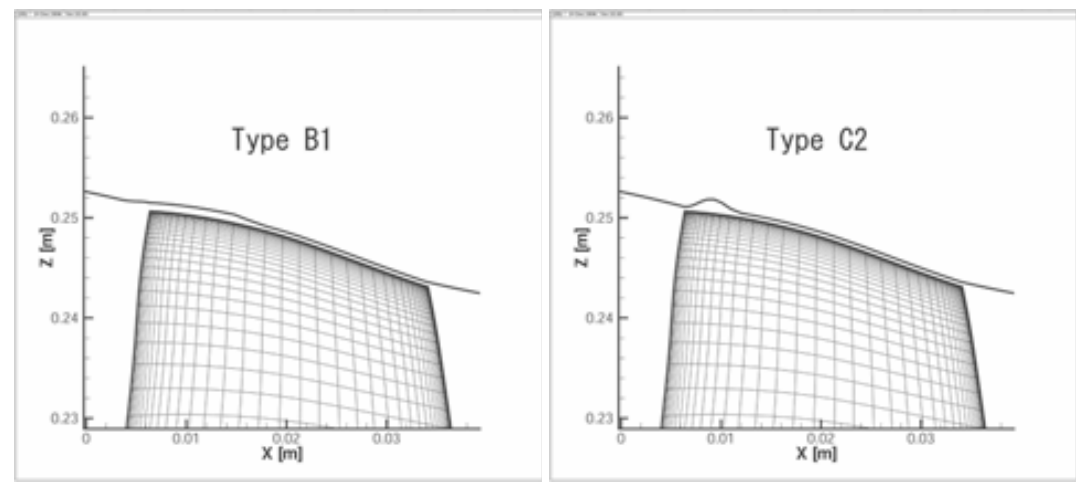

Fig. 11. Endwall casing contouring (Ito et al., 2007)

\subsection{Slot-type treatments}

Another way to treat the casing with the aim to improve the rotor performance and stability is exemplified in Fig. 12. Here the casing wall is circumferentially treated with a discrete number of axial rectangular slots over the blade tip section.

A similar slot-type casing treatment consisting of four identical axial slots per blade passage and having an open area of $50 \%$ in the circumferential direction has been also proposed. (Wilke and Kau, 2004). In this case, the slots are parallel to the rotation axis and inclined by $45^{\circ}$ against the meridional plane in the direction of rotor rotation. The slot shape is designed as a semi-circle. Two configurations have been numerically tested. In configuration 1, the position of the slots is centered above the rotor blade tip reaching from $7.5 \%$ to $92.5 \%$ chord length. In configuration 2, the slots are moved upstream so that only $25 \%$ chord length remains covered by the casing treatment.

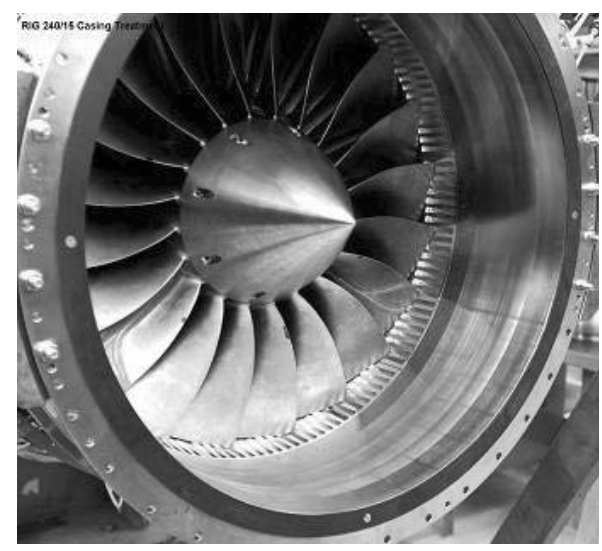

Fig. 12. EJ200 LPC with axial slots casing treatment (Broichhausen \& Ziegler, 2005) 
For both configurations, simulations showed a significant increment in flow stability compared to the solid wall, the stalling mass flow passed from $0.95 \%$ to $0.75 \%$ the design mass flow at the design speed. It was observed that the stabilizing effects are based on the positive impact of casing treatment on the tip clearance flow and its resulting vortex. Configuration 1 led to a massive destruction of the tip leakage vortex, whereas configuration 2 weakened the rolling-up of the tip clearance flow. Configuration 2, gave also a positive impact on the overall efficiency.

\section{Air injection and bleeding}

One of the first flow control ideas to receive a considerable attention in gas turbine applications is the flow injection and bleeding concept. Air injection near the blade tips has proved to increase compressor stall margin, leading to higher engine operability. Fig. 13 shows a set of successful 12 non-intrusive prototype injectors recently installed in the casing of a transonic compressor test rotor. On the other hand, aspiration (or bleeding) can be used to delay blade separation, which limits the stage work and therefore increases the required number of stages. Doubling the work per stage using aspiration results in a dramatic reduction in the number of stages, though not necessarily an exactly proportional reduction in compressor weight due to the added complexity of blades and added plumbing. For fighter applications this technology looks very attractive due to its potential to improve the thrust/weight ratio of the engine.



Fig. 13. Discrete tip injection (Hathaway, 2007)

\subsection{Air injection}

Measurements and simulations for active discrete tip injection have been presented for a range of steady injection rates and distributions of injectors around the annulus of a tipcritical transonic compressor rotor operating in isolation (Suder et al., 2001). In such case, casing-mounted injectors were located at $200 \%$ tip axial chord upstream of the rotor. Each injector penetrated $6 \%$ span from the casing into the flow field. The simulations indicated that tip injection increases stability by unloading the rotor tip. Tip injection decreases 
incidence and blade loading at the tip, allowing increased loading at lower blade spans before the blade stalls. With tip injection present, the blade stalls when the loading at the tip reaches the level equal to that for which the blade stalls with no injection. The experiments showed that stability enhancement is related to the mass averaged axial velocity at the tip. For the tested rotor, experimental results demonstrated that at $70 \%$ speed the stalling flow coefficient can be reduced by $30 \%$ using an injected mass flow equivalent to $1 \%$ of the annulus flow. At design speed, the stalling flow coefficient was reduced by $6 \%$ using an injected mass flow equivalent to $2 \%$ of the annulus flow. Tip injection has also been demonstrated as an effective tool for recovering a compressor from fully developed stall.

In a self-induced (passive) solution, steady discrete tip injection using casing recirculation has been simulated in a single transonic fan rotor (Hathaway, 2002). The idea was to bleed pressurized fluid from downstream of the rotor and properly inject it upstream. Simulations were carried out assuming both a clear and distorted inlet flow. The distortion was circumferentially applied near the casing endwall fixing a lower inlet total pressure. The recirculation model gave $125 \%$ range extension without inlet distortion and $225 \%$ range extension with inlet distortion, without significant impact on overall efficiency.

Such a solution has been successively tested on a single-stage transonic compressor (Strazisar et al., 2004). Results clearly indicated that recirculation extends the stable operating range of that stage to lower mass flows than that can be achieved without recirculation. With the recirculation activated, the positive change in stalling flow coefficient was $6 \%$ at $70 \%$ of design speed and $2 \%$ at design speed, with a total injected flow of $0.9 \%$ of the annulus flow at both operating speeds. In the same work, the potential for using endwall recirculation to increase the stability of transonic highly loaded multistage compressors was demonstrated through results from a rig test of simulated recirculation driving both a steady injected flow and an unsteady injected flow. Unsteady injection increased stability more than steady injection and was capable of changing the unsteady near stall dynamics of the multistage compressor.

\subsection{Bleeding}

Fig. 14 shows the sketch of a transonic aspirated stage experimentally tested and numerically investigated to demonstrate the application of boundary layer aspiration for increasing the stage work (Schuler et al., 2005). The stage was designed to produce a pressure ratio of 1.6 at a tip speed of $750 \mathrm{ft} / \mathrm{s}$ resulting in a stage work coefficient of 0.88 . The primary aspiration requirement for the stage was a bleed fraction $0.5 \%$ of the inlet mass flow on the rotor and stator suction surfaces. Additional aspiration totalling $2.8 \%$ was also used at shock impingement locations and other locations on the hub and casing walls. The stage achieved a peak pressure ratio of 1.58 and through flow efficiency of $90 \%$ at the design point. The rotor showed an extremely high efficiency of $97 \%$ for a transonic rotor, partially attributed to aspiration and partially to the elimination of the tip clearance flow due to the tip shroud. Aspiration was also effective in maintaining stage performance at off-design conditions. The experimental data showed unstalled stage performance at least $83 \%$ of the design mass flow.

The possibility of a very high pressure ratio per single-stage using aspiration has been demonstrated for the fan of Fig. 15. The fan stage has been designed to achieve a pressure ratio of 3.4 at $1500 \mathrm{ft} / \mathrm{s}$. The low energy viscous flow was aspirated from diffusion-limiting locations on the blades and flow path surfaces. Experimental results gave a stage pressure 
ratio exceeding 3 at design speed, with an aspiration flow fraction of 3.5\% of the stage inlet mass flow. CFD simulations showed that aspiration fixes the passage shock position, particularly in the tip region, maintaining good aerodynamic behaviour at off-design operating points.

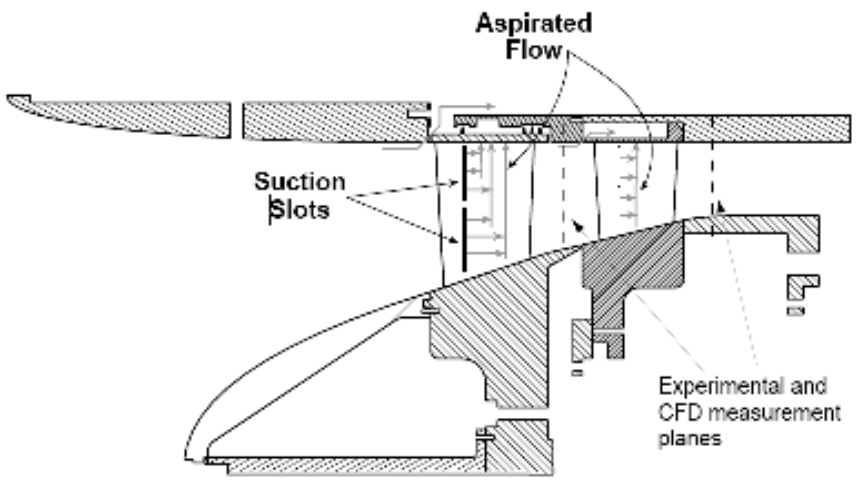

Fig. 14. A tested suction configuration (Schuler et al., 2002)


Fig. 15. Test package (left) and rotor aspiration scheme (right) (Merchant et al., 2005)

In a previous work (Dang \& Van Rooij, 2003), it was demonstrated the possibility to reduce the amount of aspiration without compromise its benefits. When used as an add-on to an existing design, aspiration can require excessive amounts of suction, whereas with a blade/ aspiration scheme coupled design a significantly lower amount of suction can be needed. A baseline supersonic rotor with 56 blades was used in that work as the starting point. The blade count in that rotor was then reduced to 42 blades, and it was found that $2 \%$ of flow suction was needed to pull the shock back into the blade passage for the required back pressure. The aspiration zone was located approximately behind the shock on the suction surface from hub to $95 \%$ span. With 42 blades, inspection of the flow field showed that the peak Mach number and loading were significantly higher than in the baseline blade case, resulting in increased shock losses, thickening of the blade suction surface boundary layer, and a large region of low momentum fluid in the tip clearance region.

A new pressure loading shape was developed to mitigate the situation. The new design was shown to have better efficiency potential and a cleaner casing endwall flow using only $0.3 \%$ 
flow suction. It was also shown that the constant speed throttling characteristic of the new design can be tailored by using varying amounts of suction (up to $2 \%$ ) to hold the passage shock stationary thereby making it possible to satisfy multiple operating conditions with minimal aerodynamic penalty.

\section{Conclusions}

Transonic compressors are the state-of-art in the compression system of today's civil and military aero engines. Their capability to provide high pressure ratios maintaining high efficiencies made them preferable to both subsonic (lower pressure ratio) and supersonic (lower efficiency) solutions.

The researches of last decades have greatly contributed to their success. The progress made in optical measurement techniques and the development of computational methods led to a deep understanding of the loss mechanisms associated with their inherent supersonic relative flow, making it possible significant aerodynamic improvements and industrial diffusion.

Nowadays there is still space for further radical improvements and new solutions will be developed in the next future, like highly effective stall/surge control systems and higher pressure ratio configurations, or even new concepts based on new advanced working principles.

\section{References}

Ahn, C.-S. \& Kim, K.-Y. (2002). Aerodynamic Design Optimization of an Axial Flow Compressor Rotor, Proceedings of ASME Turbo Expo 2002, GT-2002-30445

Beheshti, B. H.; Teixeira, J. A.; Ivey, P. C.; Ghorbanian, K. \& Farhanieh, B. (2004). Parametric Study of Tip Clearance - Casing Treatment on Performance and Stability of a Transonic Axial Compressor, Proceedings of ASME Turbo Expo 2004, GT2004-53390

Benini, E. \& Biollo, R. (2007). Aerodynamics of Swept and Leaned Transonic CompressorRotors, Applied Energy, Vol. 84, No. 10, (October 2007), pp. 1012-1027, ISSN 03062619

Benini, E. \& Biollo, R. (2008). Effect of Forward and Aft Lean on the Performance of a Transonic Compressor Rotor, International Journal of Turbo and Jet Engines, Vol. 25, No. 1, (2008), pp. 13-26, ISSN 0334-0082

Bergner, J.; Hennecke, D. K. \& Hah, C. (2005a). Tip-Clearance Variations of an Axial HighSpeed Single-Stage Transonic Compressor, Proceedings of $17^{\text {th }}$ Symposium on AirBreathing Engines, ISABE-2005-1096

Bergner, J.; Kablitz, S.; Hennecke, D. K.; Passrucker, H. \& Steinhardt, E. (2005b). Influence of Sweep on the 3D Shock Structure in an Axial Transonic Compressor, Proceedings of ASME Turbo Expo 2005, GT2005-68835

Biollo, R. \& Benini, E. (2008a). Impact of Sweep and Lean on the Aerodynamic Behaviour of Transonic Compressor Rotors, Proceedings of The Future of Gas Turbine Technology $4^{\text {th }}$ International Conference, IGTC08_P17

Biollo, R. \& Benini, E. (2008b). Aerodynamic Behaviour of a Novel Three-Dimensional Shaped Transonic Compressor Rotor Blade, Proceedings of ASME Turbo Expo 2008, GT2008-51397 
Blaha, C.; Kablitz, S.; Hennecke, D. K.; Schmidt-Eisenlohr, U.; Pirker, K. \& Haselhoff, S. (2000). Numerical Investigation of the Flow in an Aft-Swept Transonic Compressor Rotor, Proceedings of ASME Turbo Expo 2000, 2000-GT-0490

Broichhausen, K. D. \& Ziegler, K. U. (2005). Supersonic and Transonic Compressors: Past, Status and Technology Trends, Proceedings of ASME Turbo Expo 2005, GT2005-69067

Burguburu, S.; Toussaint, C.; Bonhomme, C. \& Leroy, G. (2004). Numerical Optimization of Turbomachinery Bladings, ASME Journal of Turbomachinery, Vol. 126, No. 1, (January 2004), pp. 91-100, ISSN 0889-504X

Calvert, W. J.; Emmerson, P. R. \& Moore J. M. (2003). Design, Test and Analysis of a HighPressure-Ratio Transonic Fan, Proceedings of ASME Turbo Expo 2003, GT2003-38302

Calvert, W. J. \& Stapleton, A.W. (1994). Detailed Flow Measurements and Predictions for a Three-Stage Transonic Fan, ASME Journal of Turbomachinery, Vol.116, No.2, (April 1994), pp. 298-305, ISSN 0889-504X

Chen, G. T.; Greitzer, E. M.; Tan, C. S. \& Marble, F. E. (1991). Similarity Analysis of Compressor Tip Clearance Flow Structure, ASME Journal of Turbomachinery, Vol. 113, No. 2, (April 1991), pp. 260-229, ISSN 0889-504X

Chen, N.; Zhang, H.; Xu, Y. \& Huang, W. (2007). Blade Parameterization and Aerodynamic Design Optimization for a 3D Transonic Compressor Rotor, Journal of Thermal Science, Vol. 16, No. 2, (May 2007), pp. 105-114, ISSN 1003-2169

Chima, R. V. (1998). Calculation of Tip Clearance Effects in a Transonic Compressor Rotor, ASME Journal of Turbomachinery, Vol. 120, No. 1, (January 1998), pp. 131-140, ISSN 0889-504X

Copenhaver, W. W.; Mayhew, E. R.; Hah, C. \& Wadia, A. R. (1996). The Effect of Tip Clearance on a Swept Transonic Compressor Rotor, ASME Journal of Turbomachinery, Vol. 118, No. 2, (April 1996), pp. 230-229, ISSN 0889-504X

Cumpsty, N. A. (1989). Compressor Aerodynamics, Longman Group UK Limited 1989

Dang, T.Q. \& Van Rooij, M. (2003). Design of Aspirated Compressor Blades Using ThreeDimensional Inverse Method, NASA Report No. TM-2003-212212

Day, I. J. (1993). Stall Inception in Axial Flow Compressors, ASME Journal of Turbomachinery, Vol. 115, No. 1, (January 1993), pp. 1-9, ISSN 0889-504X

Denton, J. D. (2002). The Effects of Lean and Sweep on Transonic Fan Performance: A Computational Study, Task Quarterly, Vol. 6, No. 1, (2002), pp. 7-23

Denton, J. D. \& Xu, L. (1999). The Exploitation of Three-Dimensional Flow in Turbomachinery Design, Proc Instn Mech Engrs, Part C: Journal of Mechanical Engineering Science, Vol. 213, No. 2, (1999), pp. 125-137, ISSN 0954-4062

Denton, J. D. \& Xu, L. (2002). The Effects of Lean and Sweep on Transonic Fan Performance, Proceedings of ASME Turbo Expo 2002, GT-2002-30327

Epstein, A. H. (1977). Quantitative Density Visualization in a Transonic Compressor Rotor, ASME Journal of Engineering for Power, Vol.99, No.3, (July 1977), pp. 460-475, ISSN 0022-0825

Estevadeordal, J.; Gorrell, S. E. \& Copenhaver, W. W. (2007). PIV Study of Wake-Rotor Interactions in a Transonic Compressor at Various Operating Conditions, Journal of Propulsion and Power, Vol. 23, No. 1, (Jan-Feb 2007), ISSN 0748-4658 
Freeman, C. \& Cumpsty, N. A. (1992). Method for the Prediction of Supersonic Compressor Blade Performance, Journal of Propulsion and Power, Vol. 8, No. 1, (Jan-Feb 1992), pp. 199-208, ISSN 0748-4658

Gerolymos, G. A. \& Vallet, I. (1999). Tip-Clearance and Secondary Flows in a Transonic Compressor Rotor, ASME Journal of Turbomachinery, Vol. 121, No. 4, (October 1999), pp. 751-762, ISSN 0889-504X

Hah, C . \& Loellbach, J. (1999). Development of Hub Corner Stall and Its Influence on the Performance of Axial Compressor Blade Rows, ASME Journal of Turbomachinery, Vol. 121, No. 1, (January 1999), pp. 67-77, ISSN 0889-504X

Hah, C.; Puterbaugh, S. L. \& Wadia, A. R. (1998). Control of Shock Structure and Secondary Flow Field Inside Transonic Compressor Rotors Through Aerodynamic Sweep, Proceedings of the 1998 International Gas Turbine $\mathcal{E}$ Aeroengine Congress $\mathcal{E}$ Exibition, ASME Paper 98-GT-561

Hah, C.; Rabe, D. C. \& Wadia, A. R. (2004). Role of Tip-Leakage Vortices and Passage Shock in Stall Inception in a Swept Transonic Compressor Rotor, Proceedings of ASME Turbo Expo 2004, GT2004-53867

Hah, C. \& Reid, L. (1992). A Viscous Flow Study of Shock-Boundary Layer Interaction, Radial Transport, and Wake Development in a Transonic Compressor, ASME Journal of Turbomachinery, Vol. 114, No. 3, (July 1992), pp. 538-547, ISSN 0889-504X

Hathaway, M. D. (2002). Self-Recirculating Casing Treatment Concept for Enhanced Compressor Performance, Proceedings of ASME Turbo Expo 2002, GT-2002-30368

Hathaway, M. D. (2007). Passive Endwall Treatments for Enhancing Stability, NASA Report No. TM-2007-214409

Hofmann, W. \& Ballmann, J. (2002). Tip Clearance Vortex Development and Shock-VortexInteraction in a Transonic Axial Compressor Rotor, Proceedings of $40^{\text {th }}$ AIAA Aerospace Sciences Meeting and Exhibit, AIAA 2002-0083

Ito, Y.; Watanabe, T. \& Himeno, T. (2007). Effect of Endwall Contouring on Flow Instability of Transonic Compressor, Proceedings of the International Gas Turbine Congress 2007 Tokyo, IGTC2007 Tokyo TS-042

Jang, C.-M.; Samad, A. \& Kim, K.-Y. (2006). Optimal Design of Swept, Leaned and Skewed Blades in a Transonic Axial Compressor, Proceedings of ASME Turbo Expo 2006, GT2006-90384

Kablitz, S.; Bergner, J.; Hennecke, K.; Beversdorff, M. \& Schodl, R. (2003a). Darmstadt Rotor No. 2, III: Experimental Analysis of an Aft-Swept Axial Transonic Compressor Stage, International Journal of Rotating Machinery, Vol. 9, No. 6, (2003), pp. 393-402, ISSN 1023-621X

Kablitz, S.; Passrucker, H.; Hennecke, D. K. \& Engber, M. (2003b). Experimental Analysis of the Influence of Sweep on Tip Leakage Vortex Structure of an Axial Transonic Compressor Stage, Proceedings of $16^{\text {th }}$ Symposium on Air-Breathing Engines, ISABE2003-1226

König, W. M.; Hennecke, D. K. \& Fottner L. (1996). Improved Blade Profile Loss and Deviation Angle Models for Advanced Transonic Compressor Bladings: Part II-A Model for Supersonic Flow, ASME Journal of Turbomachinery, Vol. 118, No. 1, (January 1996), pp. 81-87, ISSN 0889-504X 
Law, C. H. and Wadia, A. R. (1993). Low Aspect Ratio Transonic Rotors: Part 1-Baseline Design and Performance, ASME Journal of Turbomachinery, Vol. 115, No. 2, (April 1993), pp. 218-225, ISSN 0889-504X

Lian, Y. \& Liou, M.-S. (2005). Multi-Objective Optimization of Transonic Compressor Blade Using Evolutionary Algorithm, Journal of Propulsion and Power, Vol. 21, No. 6, (NovDec 2005), pp. 979-987, ISSN 0748-4658

Merchant, A.; Kerrebrock, J. L.; Adamczyk, J. J. \& Braunscheidel, E. (2005). Experimental Investigation of a High Pressure Ratio Aspirated Fan Stage, ASME Journal of Turbomachinery, Vol. 127, No. 1, (January 2005), pp. 43-51, ISSN 0889-504X

Miller, G. R.; Lewis, Jr., G. W. \& Hartmann, M. J. (1961). Shock Losses in Transonic Compressor Blade Rows, ASME Journal of Engineering for Power, Vol. 83, No. 3, (July 1961), pp. 235-242, ISSN 0022-0825

Müller, M. W.; Biela, C.; Schiffer H.-P. \& Hah, C. (2008). Interaction of Rotor and Casing Treatment Flow in an Axial Single-Stage Transonic Compressor With Circumferential Grooves, Proceedings of ASME Turbo Expo 2008, GT2008-50135

Ning, F. \& Xu, L. (2001). Numerical Investigation of Transonic Compressor Rotor Flow Using an Implicit 3D Flow Solver With One-Equation Spalart-Allmaras Turbulence Model, Proceedings of ASME Turbo Expo 2001, 2001-GT-0359

Oyama, A.; Liou, M.-S. \& Obayashi, S. (2004). Transonic Axial-Flow Blade Optimization: Evolutionary Algorithms/Three-Dimensional Navier-Stokes Solver, Journal of Propulsion and Power, Vol. 20, No. 4, (Jul-Aug 2004), pp. 612-619, ISSN 0748-4658

Passrucker, H.; Engber, M.; Kablitz, S. \& Hennecke, D. K. (2003). Effect of Forward Sweep in a Transonic Compressor Rotor, Proc Instn Mech Engrs, Part A: Journal of Power and Energy, Vol. 217, No. 4, (2003), pp. 357-365, ISSN 0957-6509

Prasad, A. (2003). Evolution of Upstream Propagating Shock Waves From a Transonic Compressor Rotor, ASME Journal of Turbomachinery, Vol. 125, No. 1, (January 2003), pp. 133-140, ISSN 0889-504X

Puterbaugh, S. L. \& Brendel, M. (1997). Tip Clearance Flow-Shock Interaction in a Transonic Compressor Rotor, Journal of Propulsion and Power, Vol. 13, No. 1, (Jan-Feb 1997), pp. 24-30, ISSN 0748-4658

Puterbaugh, S. L.; Copenhaver, W. W.; Hah, C. \& Wennerstrom, A. J. (1997). A ThreeDimensional Shock Loss Model Applied to an Aft-Swept, Transonic Compressor Rotor, ASME Journal of Turbomachinery, Vol. 119, No. 3, (July 1997), pp. 452-459, ISSN 0889-504X

Rabe, D. C. \& Hah, C. (2002). Application of Casing Circumferential Grooves for Improved Stall Margin in a Transonic Axial Compressor, Proceedings of ASME Turbo Expo 2002, GT-2002-30641

Reid, L. \& Moore, R. D. (1978). Design and Overall Performance of Four Highly Loaded, High-Speed Inlet Stages for an Advanced High-Pressure-Ratio Core Compressor, NASA TP 1337

Schuler, B. J.; Kerrebrock, J. L. \& Merchant, A. (2005). Experimental Investigation of a Transonic Aspirated Compressor, ASME Journal of Turbomachinery, Vol. 127, No. 2, (April 2005), pp. 340-348, ISSN 0889-504X 
Schuler, B. J.; Kerrebrock, J. L. \& Merchant, A. (2002). Experimental Investigation of an Aspirated Fan Stage, Proceedings of ASME Turbo Expo 2002, GT-2002-30370

Strazisar, A. J. (1985). Investigation of Flow Phenomena in a Transonic Fan Rotor Using Laser Anemometry, ASME Journal of Engineering for Gas Turbines and Power, Vol.107, No.2, (April 1985), pp. 427-435, ISSN 0742-4795

Strazisar, A. J.; Wood, J. R.; Hathaway, M. D. \& Suder, K. L. (1989). Laser Anemometer Measurements in a Transonic Axial-Flow Fan Rotor, NASA TP 2879

Strazisar, A. J.; Bright, M. M.; Thorp, S.; Culley, D. E. \& Suder, K. L. (2004). Compressor Stall Control Through Endwall Recirculation, Proceedings of ASME Turbo Expo 2004, GT2004-54295

Suder, K. L. (1998). Blockage Development in a Transonic, Axial Compressor Rotor, ASME Journal of Turbomachinery, Vol. 120, No. 3, (July 1998), pp. 465-476, ISSN 0889-504X

Suder, K. L. \& Celestina, M. L. (1996). Experimental and Computational Investigation of the Tip Clearance Flow in a Transonic Axial Compressor Rotor, ASME Journal of Turbomachinery, Vol. 118, No. 2, (April 1996), pp. 218-229, ISSN 0889-504X

Suder, K. L.; Chima, R. V.; Strazisar, A. J. \& Roberts, W. B. (1995). The Effect of Adding Roughness and Thickness to a Transonic Axial Compressor Rotor, ASME Journal of Turbomachinery, Vol. 117, No. 4, (October 1995), pp. 491-505, ISSN 0889-504X

Suder, K. L.; Hathaway, M. D.; Thorp, S. A.; Strazisar, A. J. \& Bright, M. B. (2001). Compressor Stability Enhancement Using Discrete Tip Injection, ASME Journal of Turbomachinery, Vol. 123, No. 1, (January 2001), pp. 14-23, ISSN 0889-504X

Sun, Y.; Ren, Y.-X.; Fu, S.; Wadia, A. R. \& Wisler, D. (2007). Numerical Study of the Loss in a Compressor Stage, Proceedings of the International Gas Turbine Congress 2007 Tokyo, IGTC2007 Tokyo TS-041

Wadia, A. R. \& Copenhaver, W. W. (1996). An Investigation of the Effect of Cascade Area Ratios on Transonic Compressor Performance, ASME Journal of Turbomachinery, Vol. 118, No. 4, (October 1996), pp. 760-770, ISSN 0889-504X

Wadia, A. R. \& Law, C. H. (1993). Low Aspect Ratio Transonic Rotors: Part 2-Influence of Location of Maximum Thickness on Transonic Compressor Performance, ASME Journal of Turbomachinery, Vol. 115, No. 2, (April 1993), pp. 226-239, ISSN 0889-504X

Wadia, A. R.; Szucs, P. N. \& Crall, D. W. (1998). Inner Workings of Aerodynamic Sweep, ASME Journal of Turbomachinery, Vol. 120, No. 4, (October 1998), pp. 671-682, ISSN 0889-504X

Weber, A.; Schreiber, H.-A.; Fuchs, R. \& Steinert, W. (2002). 3-D Transonic Flow in a Compressor Cascade With Shock-Induced Corner Stall, ASME Journal of Turbomachinery, Vol. 124, No. 3, (July 2002), pp. 358-366, ISSN 0889-504X

Wennerstrom, A. J. \& Puterbaugh, S. L. (1984). A Three-Dimensional Model for the Prediction of Shock Losses in Compressor Blade Rows, ASME Journal of Engineering for Gas Turbines and Power, Vol. 106, No. 2, (April 1984), pp. 295-299, ISSN 0742-4795

Weyer, H. B. \& Dunker, R. (1978). Laser Anemometry Study of the Flow Field in a Transonic Compressor Rotor, Proceedings of AIAA Aerospace Sciences Meeting 1978, AIAA Paper 78-1 
Wilke, I. \& Kau, H.-P. (2004). A Numerical Investigation of the Flow Mechanisms in a High pressure Compressor Front Stage With Axial Slots, ASME Journal of Turbomachinery, Vol. 126, No. 3, (July 2004), pp. 339-349, ISSN 0889-504X

Yamada, K.; Furukawa, M.; Nakano, T.; Inoue, M. \& Funazaki, K. (2004). Unsteady ThreeDimensional Flow Phenomena Due to Breakdown of Tip Leakage Vortex in a Transonic Axial Compressor Rotor, Proceedings of ASME Turbo Expo 2004, GT200453745

Yi, W.; Huang, H. \& Han, W. (2006). Design Optimization of Transonic Compressor Rotor Using CFD and Genetic Algorithm, Proceedings of ASME Turbo Expo 2006, GT200690155 


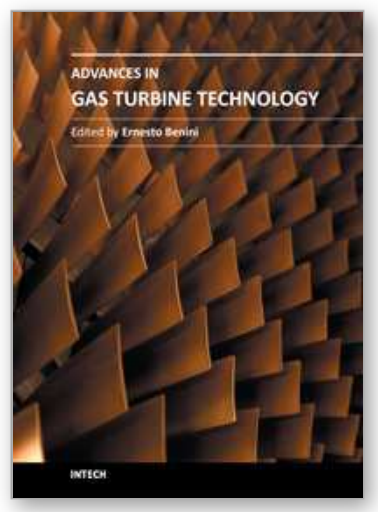

\author{
Advances in Gas Turbine Technology \\ Edited by Dr. Ernesto Benini
}

ISBN 978-953-307-611-9

Hard cover, 526 pages

Publisher InTech

Published online 04, November, 2011

Published in print edition November, 2011

Gas turbine engines will still represent a key technology in the next 20-year energy scenarios, either in standalone applications or in combination with other power generation equipment. This book intends in fact to provide an updated picture as well as a perspective vision of some of the major improvements that characterize the gas turbine technology in different applications, from marine and aircraft propulsion to industrial and stationary power generation. Therefore, the target audience for it involves design, analyst, materials and maintenance engineers. Also manufacturers, researchers and scientists will benefit from the timely and accurate information provided in this volume. The book is organized into five main sections including 21 chapters overall: (I) Aero and Marine Gas Turbines, (II) Gas Turbine Systems, (III) Heat Transfer, (IV) Combustion and (V) Materials and Fabrication.

\title{
How to reference
}

In order to correctly reference this scholarly work, feel free to copy and paste the following:

Roberto Biollo and Ernesto Benini (2011). State-of-Art of Transonic Axial Compressors, Advances in Gas Turbine Technology, Dr. Ernesto Benini (Ed.), ISBN: 978-953-307-611-9, InTech, Available from: http://www.intechopen.com/books/advances-in-gas-turbine-technology/state-of-art-of-transonic-axialcompressors

\section{INTECH}

open science | open minds

\author{
InTech Europe \\ University Campus STeP Ri \\ Slavka Krautzeka 83/A \\ 51000 Rijeka, Croatia \\ Phone: +385 (51) 770447 \\ Fax: +385 (51) 686166 \\ www.intechopen.com
}

\author{
InTech China \\ Unit 405, Office Block, Hotel Equatorial Shanghai \\ No.65, Yan An Road (West), Shanghai, 200040, China \\ 中国上海市延安西路65号上海国际贵都大饭店办公楼 405 单元 \\ Phone: +86-21-62489820 \\ Fax: $+86-21-62489821$
}


(C) 2011 The Author(s). Licensee IntechOpen. This is an open access article distributed under the terms of the Creative Commons Attribution 3.0 License, which permits unrestricted use, distribution, and reproduction in any medium, provided the original work is properly cited. 